\title{
Atypical antipsychotic agents; Peas in a pod or chalk and cheese?
}

\author{
Ajeet B Singh ${ }^{1 *}$, Andrew A Nierenberg ${ }^{1,6}$, Lakshmi N Yatham and Michael Berk 1,2,3,4,5
}

\begin{abstract}
With escalating health expenditure and a shrinking purse, there is increased focus on the cost efficacy of still patented versus generic medications in general, and for atypical antipsychotics in particular. In a recent BMC Medicine article, Godman and colleagues presented data indicating poor uptake of the off patent atypical antipsychotic risperidone, arguing for authorities to mandate its greater use. This is under the assumption of clinical equivalence of atypical antipsychotics. This commentary argues that there are clinically meaningful differences between atypical antipsychotics and important inter-individual heterogeneity in clinical response and tolerability. Access to a broad range of atypical antipsychotics enables clinicians to tailor care, taking consideration of differential efficacy and adverse effects profile in order to meet the needs of individual patients with improved real world effectiveness of treatment. Restriction of agent choice risks detracting from optimal clinical care, with possible poorer outcomes and greater costs of care. A balance between encouraging use of cheapest in class agent and allowing access to various atypical agents for tailored care is likely to produce optimal health outcomes.

Please see related article: http://www.biomedcentral.com/1741-7015/12/98.
\end{abstract}

Keywords: Atypical antipsychotics, Risperidone, Bipolar, Schizophrenia, Generic, Health economics

\section{Background}

In an economic climate characterised by rising public debt, sluggish economic growth and rapidly expanding health care expenditures, there is increasing pressure on restraining the pace of growth of the health care budget. Pharmaceutical expenditure is a large and growing segment of this budget and an attractive target for cost reduction. In an article recently published in BMC Medicine, Godman and colleagues [1] present data from an international retrospective association study of risperidone prescribing rates 20 months before and 20 months after cheaper generic brands became available in several European countries. Interestingly, their data indicate that once generic risperidone was available, it was prescribed less (as a proportion of all atypical antipsychotic scripts), and there was a wide variance between countries in the proportion of risperidone scripts that were generic versus brand name. Furthermore, among newly initiated patients

\footnotetext{
* Correspondence: a.singh@deakin.edu.au

${ }^{1}$ IMPACT Strategic Research Centre, School of Medicine, Deakin University, PO Box 281, Geelong 3220, Australia

Full list of author information is available at the end of the article
}

prescribed atypical antipsychotics there was no increased prescribing of generic risperidone when it may have been a valid treatment option. The authors argue that their data have significant implications for health care costs and suggest that health authorities encourage prescribing of cheaper generics versus allowing prescribers to tailor treatment to patient needs based on differential medication side effect and efficacy profiles. We submit that third party payers mandating the use of cheaper generic atypical antipsychotics as first line agents in schizophrenia and bipolar disorders raises important but complex issues meriting debate.

\section{Differential efficacy profiles of atypical antipsychotics}

Atypical antipsychotics are now among the most widely used agents and the bulk of this use - at least in western countries - is for non-psychotic indications, principally mood disorders. The efficacy of individual atypical antipsychotic agents varies by both condition (schizophrenia or bipolar disorder) and phase of illness (particularly bipolar depression). As an exemplar, clozapine has established 
greater symptom efficacy than other atypical antipsychotics in the treatment of schizophrenia [2], but due to side effect and toxicity profile is not used as a first line agent [3]. Subtle differences in efficacy between other atypical antipsychotics in the treatment of schizophrenia - particularly in improving negative symptoms - arguably exist, but it is unclear whether this is an artefact of methodological variance $[2,4]$. Importantly, while atypical antipsychotics have equal efficacy in treating mania, they clearly have differential efficacy in the depressive phase of bipolar disorder [5,6], with agents such as quetipine and lurasidone demonstrating efficacy while aripiprazole, ziprasidone and risperidone have failed to show consistent benefit and, hence, are not recommended for the management of the depressive phase of bipolar disorder [6]. Similarly, in unipolar depression, only quetiapine has been shown to be effective in monotherapy. Atypical antipsychotics are also widely used as adjuncts to antidepressants to treat refractory unipolar major depression, and here again, while quetiapine, aripiprazole, risperidone and olanzapine have efficacy based on meta-analytical data, the number needed to treat for response and remission are much higher and the number needed to harm are much lower for olanzapine compared with other atypical antipsychotics [7]. Furthermore, another atypical antipsychotic ziprasidone does not have demonstrated efficacy [8,9]. Differential efficacy of atypical antipsychotics for other clinical uses has been less thoroughly investigated, but risperidone may have utility in dementia associated agitation and obsessive compulsive disorder, but poorer efficacy for generalized anxiety disorder than some other atypical agents, such as quetiapine [10]. Indeed, this inconsistent pattern of efficacy of antipsychotic agents in non-psychotic disorders argues strongly against the presence of a class effect. These agents, in reality, have markedly divergent pharmacodynamics and pharmacokinetics and, while there is consensus that activity against dopamine type 2 receptors is necessary for antipsychotic efficacy [11], there is considerable uncertainty as to which of the multiplicity of actions these agents have may drive their effects in mood disorders $[12,13]$.

\section{Differential tolerability profiles of atypical antipsychotics} Atypical antipsychotics also have widely differing side effect and tolerability profiles. This is of critical clinical importance as tolerability is one factor driving adherence [14], and medication adherence markedly influences both clinical course and cost of care $[15,16]$. In the case of risperidone, more extrapyramidal side effects, greater prolactin elevation, and greater weight gain than with some other atypical antipsychotics have been described in recent high profile reviews $[2,17]$. Elevation of prolactin appears to be particularly marked with risperidone compared to other atypical agents [2] and is associated with hypogonadism, reproductive dysfunction, gynecomastia and bone loss [18]. Osteoporosis and fracture risk is an adverse effect of diverse psychotropic agents attracting increasing recent attention, and one where very clear between-agent differences are apparent $[19,20]$. Risperidone is, however, less associated with the metabolic syndrome than other agents, particularly olanzapine, quetiapine and clozapine [6]. Trend level differences for all cause medication discontinuation have been noted with risperidone, trending toward greater discontinuation than some other atypical agents - putatively due to differential side effect profiles and tolerability $[2,17]$. As adverse events are idiosyncratic and unpredictable, the availability of various atypical antipsychotics enables patient and prescriber to tailor treatment based on differential side effects profile, and this may enhance adherence [21]. This clinical need is reflected in international clinical practice guidelines on the management of schizophrenia and bipolar disorder - with several atypical agents considered first line options in patient care $[3,6]$.

\section{Conclusions}

Finite health resources make cost effective use of pharmaceuticals an important societal issue. Atypical antipsychotics have differing tolerability and efficacy profiles. Effectiveness in naturalistic settings is highly dependent on subjective efficacy as well as on adherence, which in turn is related to long and short term side effect profiles. While access to cheaper generic atypical antipsychotics offers an opportunity for more cost effective care, it is not without risks. Mandating switching to a generic atypical antipsychotic without any corresponding clinical indication may result in increased risk of relapse, reduced adherence, poorer outcomes and greater ultimate health care costs $[22,23]$. Reducing access to a range of atypical agents as first line treatment will hamper tailoring of medication to individual patient needs and preference, reducing clinical effectiveness and making it more difficult for clinicians to follow current best practice guidelines $[3,6]$. Nevertheless, there will be some clinical instances where use of a more cost-effective generic atypical agent (either first line or as switch to agent) may be appropriate, and ways for third party payers to encourage such behaviour merit further exploration. In the absence of data, we urge policy makers to strike a balance between tailored effective care (with choice of atypical antipsychotic agent) versus mandated use of cheapest in class agent. To obtain the data necessary for evidence-based policy, it would be useful to invest in comparative effectiveness studies that focus on: 1) outcomes of tailored versus mandated care, and 2) sufficiently powered cluster-randomized studies of key atypical antipsychotics. Our patients' health deserves no less. 


\section{Competing interests}

AB Singh, is a self-employed psychiatrist and a casual speaker for Servier Australia, Astra Zeneca Australia, Lilly Australia, Pfizer Australia, Lundbeck Australia. Michael Berk has received Grant/Research Support from the NIH, Cooperative Research Centre, Simons Autism Foundation, Cancer Council of Victoria, Stanley Medical Research Foundation, MBF, NHMRC, Beyond Blue, Rotary Health, Geelong Medical Research Foundation, Bristol Myers Squibb, Eli Lilly, Glaxo SmithKline, Meat and Livestock Board, Organon, Novartis, Mayne Pharma, Servier and Woolworths, has been a speaker for Astra Zeneca, Bristol Myers Squibb, Eli Lilly, Glaxo SmithKline, Janssen Cilag, Lundbeck, Merck, Pfizer, Sanofi Synthelabo, Servier, Solvay and Wyeth, and served as a consultant to Astra Zeneca, Bioadvantex, Bristol Myers Squibb, Eli Lilly, Glaxo SmithKline, Janssen Cilag, Lundbeck Merck and Servier. MB is supported by a NHMRC Senior Principal Research Fellowship 1059660 Lakshmi N. Yatham has been a member of the advisory boards/speaker for Astrazeneca, Bristol Myers Squibb, Dinippon Sumamito, GSK, Janssen, Lilly, Lundbeck, Merck, Pfizer, Servier and Sunvion. He has also received research grants from Astrazeneca, BMS, DSP, GSK, Janssen, Lilly, Pfizer, Servier, and Valeant. Andrew A. Nierenberg. Disclosures June 2014: Consultant: American Psychiatric Association, Appliance Computing Inc. (Mindsite), Basliea, Brain Cells, Inc., Brandeis University, Bristol Myers Squibb, Clintara, Corcept, Dey Pharmaceuticals, Dainippon Sumitomo (now Sunovion), Eli Lilly and Company, EpiQ, L.P./Mylan Inc., Forest, Genetech, GlaxoSmithKline, Hoffman LaRoche, Infomedic, Lundbeck, Medavante, Merck, Methylation Sciences, Naurex, Novartis, PamLabs, PGx Health, Ridge Diagnostics Shire, ScheringPlough, Sunovion, Takeda Pharmaceuticals, Targacept, and Teva; consulted through the MGH Clinical Trials Network and Institute (CTNI) for Astra Zeneca, Brain Cells, Inc, Dianippon Sumitomo/Sepracor, Johnson and Johnson, Labopharm, Merck, Methylation Science, Novartis, PGx Health, Shire, Schering-Plough, Targacept and Takeda/Lundbeck Pharmaceuticals. Grants/ Research support: AHRQ, Brain and Behavior Research Foundation, Cephalon, Elan, Forest, Marriott Foundation, Mylan, NIMH, PamLabs, PCORI, Pfizer Pharmaceuticals, Shire, and Takeda. Honoraria: Belvoir Publishing, University of Texas Southwestern Dallas, Hillside Hospital, American Drug Utilization Review, American Society for Clinical Psychopharmacology, Baystate Medical Center, Columbia University, CRICO, Dartmouth Medical School, IMEDEX, Israel Society for Biological Psychiatry, Johns Hopkins University, MJ Consulting, New York State, Medscape, MBL Publishing, National Association of Continuing Education, Physicians Postgraduate Press, SUNY Buffalo, University of Wisconsin, University of Pisa, University of Michigan, University of Miami, APSARD, ISBD, SciMed, Slack Publishing and Wolters Klower Publishing. Stock: Brain Cells, Inc., Medavante. Copyrights: Clinical Positive Affect Scale and the MGH Structured Clinical Interview for the Montgomery Asberg Depression Scale exclusively licensed to the MGH Clinical Trials Network and Institute (CTNI). Speaker Bureaus: none since 2003.

\section{Author information}

AS - Consultant Psychiatrist, The Geelong Clinic, Australia. Senior Clinical Lecturer and Research Fellow, Impact Strategic Research Centre, School of Medicine, Deakin University, Australia. AN - Professor of Psychiatry, Harvard Medical School, Co-Director of the Bipolar Clinic and Research Program, and Associate Director of the Depression Clinical and Research Program, Massachusetts General Hospital. LY -Professor of Psychiatry, University of British Columbia; Regional Head, Department of Psychiatry Vancouver Coastal Health and Providence Health Care; Regional Program Medical Director Mental Health and Addictions Vancouver Coastal Health and Providence Health Care. MB - Alfred Deakin Professor of Psychiatry, School of Medicine, Deakin University. Director, IMPACT Strategic Research Centre (Innovation in Mental and Physical Health and Clinical Treatment). Professorial Research Fellow, The Florey Institute of Neuroscience and Mental Health, Orygen Research Centre and the Department of Psychiatry, University of Melbourne. NHMRC Senior Principal Research Fellow.

\section{Authors' contributions}

All authors contributed to conception of the article, were involved in editing and revision of the manuscript. All authors read and approved the final manuscript.

\section{Author details}

'IMPACT Strategic Research Centre, School of Medicine, Deakin University, PO Box 281, Geelong 3220, Australia. ${ }^{2}$ Orygen Youth Health Research Centre,
Centre for Youth Mental Health, University of Melbourne, 35 Poplar Road, Parkville, Victoria 3052, Australia. ${ }^{3}$ Barwon Health and the Geelong Clinic, Swanston Centre, PO Box 281, Geelong, Victoria 3220, Australia. ${ }^{4}$ Florey Institute for Neuroscience and Mental Health, Kenneth Myer Building, Royal Parade, Parkville, Australia. ${ }^{5}$ Department of Psychiatry, University of Melbourne, 3052 Parkville, Australia. ${ }^{6}$ Bipolar Clinic and Research Program, Massachusetts General Hospital, Harvard Medical School, 50 Staniford Street, Boston, MA 02114-2517, USA. 'Department of Psychiatry, University of British Columbia, Vancouver, BC V6T 1Z3, Canada.

Received: 10 July 2014 Accepted: 10 July 2014

Published: 1 August 2014

\section{References}

1. Godman B, Petzold M, Bennett K, Bennie M, Bucsics A, Finlayson AE, Martin A, Persson M, Piessnegger J, Raschi E, Simoens S, Zara CBC: Can authorities appreciably enhance the prescribing of oral generic risperidone to conserve resources?: findings from across Europe and the implications. BMC Med 2014, 12:98.

2. Leucht S, Cipriani A, Spineli L, Mavridis D, Orey D, Richter F, Samara M, Barbui C, Engel RR, Geddes JR, Kissling W, Stapf MP, Lässig B, Salanti G, Davis JM: Comparative efficacy and tolerability of 15 antipsychotic drugs in schizophrenia: a multiple-treatments meta-analysis. Lancet 2013, 382:951-962.

3. Hasan A, Falkai P, Wobrock T, Lieberman J, Glenthoj B, Gattaz WF, Thibaut F, Möller HJ, WFSBP Task force on Treatment Guidelines for Schizophrenia: World Federation of Societies of Biological Psychiatry (WFSBP) guidelines for biological treatment of schizophrenia, part 2: update 2012 on the long-term treatment of schizophrenia and management of antipsychotic-induced side effects. World J Biol Psychiatry 2013, 14:2-44.

4. Innamorati M, Baratta S, Di Vittorio C, Lester D, Girardi P, Pompili M, Amore M: Atypical antipsychotics in the treatment of depressive and psychotic symptoms in patients with chronic schizophrenia: a naturalistic study. Schizophr Res Treatment 2013, 2013:423205.

5. Selle V, Schalkwijk S, Vázquez GH, Baldessarini RJ: Treatments for acute bipolar depression: meta-analyses of placebo-controlled, monotherapy trials of anticonvulsants, lithium and antipsychotics. Pharmacopsychiatry 2014, 47:43-52.

6. Yatham LN, Kennedy SH, Parikh SV, Schaffer A, Beaulieu S, Alda M, O'Donovan C, Macqueen G, McIntyre RS, Sharma V, Ravindran A, Young LT, Milev R, Bond DJ, Frey BN, Goldstein BI, Lafer B, Birmaher B, Ha K, Nolen WA, Berk M: Canadian Network for Mood and Anxiety Treatments (CANMAT) and International Society for Bipolar Disorders (ISBD) collaborative update of CANMAT guidelines for the management of patients with bipolar disorder: update 2013. Bipolar Disord 2013, 15:1-44.

7. Spielmans Gl, Berman MI, Linardatos E, Rosenlicht NZ, Perry A, Tsai AC Adjunctive atypical antipsychotic treatment for major depressive disorder: a meta-analysis of depression, quality of life, and safety outcomes. PLoS Med 2013, 10:e1001403.

8. Lam RW, Kennedy SH, Grigoriadis S, McIntyre RS, Milev R, Ramasubbu R, Parikh SV, Patten SB, Ravindran AV, Canadian Network for Mood and Anxiety Treatments (CANMAT): Canadian Network for Mood and Anxiety Treatments (CANMAT) clinical guidelines for the management of major depressive disorder in adults. III. Pharmacotherapy. J Affect Disord 2009, 117:S26-S43.

9. Maneeton N, Maneeton B, Srisurapanont M, Martin SD: Quetiapine monotherapy in acute phase for major depressive disorder: a meta-analysis of randomized, placebo-controlled trials. BMC Psychiatry 2012, 12:160.

10. Maher AR, Maglione M, Bagley S, Suttorp M, Hu JH, Ewing B, Wang Z, Timmer M, Sultzer D, Shekelle PG: Efficacy and comparative effectiveness of atypical antipsychotic medications for off-label uses in adults: a systematic review and meta-analysis. JAMA 2011, 306:1359-1369.

11. Nord M, Farde L: Antipsychotic occupancy of dopamine receptors in schizophrenia. CNS Neurosci Ther 2011, 17:97-103.

12. Yatham LN, Goldstein JM, Vieta E, Bowden CL, Grunze H, Post RM, Suppes T, Calabrese JR: Atypical antipsychotics in bipolar depression: potential mechanisms of action. J Clin Psychiatry 2005, 66:40-48.

13. Horacek J, Bubenikova-Valesova V, Kopecek M, Palenicek T, Dockery C, Mohr P, Höschl C: Mechanism of action of atypical antipsychotic drugs and the neurobiology of schizophrenia. CNS Drugs 2006, 20:389-409. 
14. Berk L, Hallam KT, Colom F, Vieta E, Hasty M, Macneil C, Berk M:

Enhancing medication adherence in patients with bipolar disorder. Hum Psychopharmacol 2010, 25:1-16.

15. Narasimhan M, Un Pae C, Masand N, Masand P: Partial compliance with antipsychotics and its impact on patient outcomes. Int J Psychiatry Clin Pract 2007, 11:102-111.

16. Sun SX, Liu GG, Christensen DB, Fu AZ: Review and analysis of hospitalization costs associated with antipsychotic nonadherence in the treatment of schizophrenia in the United States. Curr Med Res Opin 2007, 23:2305-2312.

17. Komossa K, Rummel-Kluge C, Schwarz S, Schmid F, Hunger H, Kissling W, Leucht S: Risperidone versus other atypical antipsychotics for schizophrenia. Cochrane Database Syst Rev 2011, 1:CD006626.

18. Ajmal A, Joffe H, Nachtigall LB: Psychotropic-induced hyperprolactinemia: a clinical review. Psychosomatics 2014, 55:29-36.

19. Williams LJ, Berk M, Henry MJ, Stuart AL, Brennan SL, Jacka FN, Pasco JA: Depression following fracture in women: a study of age-matched cohorts. BMJ Open 2014, 4:e004226.

20. Hodge JM, Wang Y, Berk M, Collier FM, Fernandes TJ, Constable MJ, Pasco JA, Dodd S, Nicholson GC, Kennedy RL, Williams L: Selective serotonin reuptake inhibitors inhibit human osteoclast and osteoblast formation and function. Biol Psychiatry 2013, 74:32-39.

21. Sacchetti E, Vita A, Siracusano A, Fleischhacker W: Adherence to Antipsychotics in Schizophrenia. Milan: Springer Milan; 2014 [Available as ebook or hard copy].

22. Essock SM, Covell NH, Davis SM, Stroup TS, Rosenheck RA, Lieberman JA: Effectiveness of switching antipsychotic medications. Am J Psychiatry 2006, 163:2090-2095.

23. Treur M, Heeg B, Möller HJ, Schmeding A, van Hout B: A pharmaco-economic analysis of patients with schizophrenia switching to generic risperidone involving a possible compliance loss. BMC Health Serv Res 2009, 9:32.

doi:10.1186/s12916-014-0126-1

Cite this article as: Singh et al:: Atypical antipsychotic agents; Peas in a pod or chalk and cheese? BMC Medicine 2014 12:126.

\section{Submit your next manuscript to BioMed Central and take full advantage of:}

- Convenient online submission

- Thorough peer review

- No space constraints or color figure charges

- Immediate publication on acceptance

- Inclusion in PubMed, CAS, Scopus and Google Scholar

- Research which is freely available for redistribution 